\title{
Prevalence and risk factors analysis associated with anaplasmosis in symptomatic cattle under field conditions in southern Khyber Pakhtoonkhwa, Pakistan
}

\author{
Naimat Ullah Khan ${ }^{1^{*}}$, Mian Saeed Sarwar ${ }^{1}$, Sultan Ayaz ${ }^{1}$, Hazrat Ali ${ }^{1}$, \\ Anwar Ali ${ }^{2}$, Ikramullah Khan ${ }^{3}$,Mumtaz Ali Khan ${ }^{3}$, Azmat Ullah Khan ${ }^{3}$, \\ Munib Hussain ${ }^{4}$, Mehboob Ali ${ }^{5}$ and Ghazunfer Rashid ${ }^{5}$ \\ 1. College of veterinary sciences and animal Husbandry, Abdul Wali Khan University Mardan, KPK-Pakistan \\ 2. Veterinary Research Institute, Peshawar, KPK-Pakistan \\ 3. Department of Livestock and Dairy Development, Peshawar, KPK-Pakistan \\ 4. Animal Health Programme, NARC, Park road Islamabad-Pakistan \\ 5. Department of livestock and Dairy Development, Quetta, Balochistan-Pakistan \\ *Corresponding author's email:naimatullahkhan19@yahoo.com,naimatullahkhan75@awkum.edu.pk \\ Citation \\ Naimat Ullah Khan, Mian Saeed Sarwar, Sultan Ayaz, Hazrat Ali, Anwar Ali, Ikramullah Khan, Mumtaz Ali Khan, \\ Azmat Ullah Khan, Munib Hussain, Mehboob Ali and Ghazunfer Rashid. Prevalence and risk factors analysis \\ associated with anaplasmosis in symptomatic cattle under field conditions in southern Khyber Pakhtoonkhwa, \\ Pakistan. Pure and Applied Biology. Vol. 8, Issue 4, pp2119-2127. http://dx.doi.org/10.19045/bspab.2019.80156
}

\begin{tabular}{llll}
\hline Received: 08/05/2019 & Revised: 14/07/2019 & Accepted: 18/07/2019 & Online First: 04/08/2019 \\
\hline
\end{tabular}

\section{Abstract}

The aim of the current study was to assess the prevalence of anaplasmosis and potential risk factors (age, sex, breed, months, seasons, application of acaricides) associated with occurrence of anaplasmosis in cattle in southern area of Khyber Pakhtunkhwa. Anaplasma is an obligate intraerythrocytic microorganism affecting a wide range of ruminants and responsible for huge economical losses in form of high mortality, weight loss and dropped milk. Overall three hundred $(\mathrm{n}=300)$ animals showing clinical signs under field conditions were randomly selected from district LakkiMarwat for a period of six months (January, 2018 to June 2018). As a result the overall prevalence was $19.66 \%$ where the highest prevalence $(24.85 \%)$ was recorded in young cattle at the age of ( $\leq 5$ years) than adults ( $\geq 5$ years) where lower prevalence $(13.13 \%)$ was reported and statistically highly significant $(\mathrm{p}<0.001)$ association was observed. The highest sex wise prevalence was recorded in female animals $(22.07 \%)$ than male $(11.59 \%)$ where significant $(\mathrm{p}<0.002)$ association was recorded. The highest breed wise prevalence was recorded in Cross Holstein Friesian cattle (28.10\%) than Indigenous pure breed cattle $(6.08 \%)$ and found significant association $(\mathrm{p}<0.0000)$. The highest month wise prevalence was recorded in the June (38\%) followed by May (34\%), March (10\%), January (8\%) while the lowest in the month of February $(6 \%)$ and recorded significant $(\mathrm{p}<0.003))$ association. The highest season wise prevalence was 
recorded in the summer $(36 \%)$ followed by spring (16\%) while the lowest in the winter (7\%) and found highly significant $(\mathrm{p}<0.0000)$ association. The highest prevalence $(23.55 \%)$ was recorded where proper acaricides were not used whereas lowest prevalence $(10.86 \%)$ was recorded in those areas where acaricides were used and observed significant association $(p<0.0002)$. For future prospective the current study was conducted to reduce the economic losses by application of technical and scientific practices and control of predisposing factors.

Keywords: Anaplasma; Anaplasma marginale; Prevalence; Risk factors; Rickettsiales

\section{Introduction}

Anaplasma is an obligate intraerythrocytic microorganism belonging to family: Anaplasmataceae, order: Rickettsiales, species: Anaplasma marginale and Anaplasma centrale. The disease caused by Anaplasma species is known as anaplasmosis. Anaplasmosis is also known as gall sickness. Anaplasmosisis commonly occur in cattle, buffalo, sheep, goat and wild ruminants. It is tick- born rickettsial microorganism causing a huge economic losses in form of weight loss, decrease in milk production, severe anemia and high mortality. Cattle are more prone to anaplasma infection as compared to buffaloes [1]. There are 20 different species of ticks responsible for transmission of anaplasmosis [2, 3] including Rhipicephalus spp., Hyalomma spp., Boophilus demacentor spp., Ixodes spp., [4] though Boophilus microplusis the major disease transmitting tick [5].Mechanical transmission also occurs by using contaminated needles or surgical blades. Anaplasmosis is clinically characterized by development of hemolytic anemia, fever, abortions, and decrease in milk production, jaundice, nervous disorder and rapid death occur in some cases $[6,7]$. Anaplasmosis mainly occur in hot, rainy and humid weather linked with abundance of ticks [8].After biting of tick, anaplasma enters in erythrocyte and start replication. As a result busting of RBCs occur known as hemolysis [9]. Cattle show clinical signs after 20 days of post bite with $15 \%$ infectivity of RBCs. [6]. Anaplasmosis is worldwide in distribution and has been reported in both cattle and buffaloes in different countries such as Italy (50\%) [10]. (De La Fuente, 2005), China (32.35\%), Costa Rica (59.6\%) [11]. Morocco (21.9\%) and Iran (50\%). In Pakistan limited information's are available from few areas such as Islamabad (66.66\%) [12], Khushab (31.43\%), Sargodha (37.14\%), Attock (75.92\%) and Rawalpindi $(24.57 \%)$ [13].

Livestock offers a lot of advantages to the poor farmers in form of milk, meat, wool and selling of leather. There are many constraints to the rearing of cattle under field conditions. Different diseases are the major constraint to the development and production of livestock. Among all diseases ectoparasites (ticks) are the major constraint causing a huge mortality and morbidity directly or indirectly in cattle [14]. Different infectious and non-infectious diseases are responsible for heavy economic losses in livestock sector. Among all protozoal disease, anaplasmosis is the most common disease causing a huge economic losses in domestic animals [15]. Cattle are highly susceptible to tick borne diseases and result in economic losses to farmers. There are only few studies have been conducted about anaplasmosis in Pakistan. Therefore the present study was designed to explore predisposing factors responsible for prevalence of anaplasmosis in local and cross breed friesian cows in southern area of Khyber Pakhtunkhwa. The major objectives of the study were to find out the prevalence and different possible risk factors associated with anaplasmosis and give useful suggestions to the department of livestock and dairy development to make effective policy for its control. 


\section{Materials and methods \\ Ethical approval}

This study was conducted after proper approval of University Ethical Committee. All the blood samples were collected with the proper permission of owner and the necessary veterinary services were provided free of cost.

\section{Study area:}

The study area Lakki Marwat lies at $32^{\circ} 36^{\prime}$ to N. Latitude, $70^{\circ} 34^{\prime}$ to R. Longitude and 986 feet above Sea Level. This area is mainly composed sand dunes and the weather is dry and heat. Rainfall is very occasional and generally occurs in July and August. According to the livestock census the total population of cattle, buffaloes, sheep and goats are 98550, 3827, 48697 and 291711 respectively.

\section{Selection of animals}

The animals were selected by simple random sampling technique from five union councils. The selection of animals were based on the basis of clinical signs such as anemia, weakness, jaundices, high temperature (104$105^{\circ} \mathrm{F}$ ), decrease milk production and finally results were confirmed by laboratory diagnosis. From each union council, 10 animals were selected per month $(n=$ $10 \times 5=50$ animals/ month) for a period of six months .Overall three hundred $(n=300)$ animals were examined for anaplasmosis. The present study was continued from January, 2018 to June 2018.

\section{Epidemiological exploration Questionnaire}

The data was collected on pretested questionnaire containing (Dichotomous or multiple choice) questions such as name of the owner with address, breed (local or cross friesian), species (cow or buffalo), sex( male or female), presence or absence of ticks, age of the animal (young $\leq 5$ years $\&$ adult $\geq 5$ years), month of sample collection, acaricide was used or not, hygienic measures( good , poor and very poor) and housing (Closed, semi closed and open).

\section{Collection of blood samples}

Blood samples $(3-5 \mathrm{ml})$ were collected from 300 cattle by puncturing ear or jugular vein with the help of sterile disposable syringe and butterfly needle and placed in EDTA containing vacutainer and transported to Veterinary Research Institute Peshawar in ice bags for further analysis according to the technique as reported by [16] after proper labelling.

\section{Giemsa staining}

Thin blood smears were prepared immediately after blood collection. Blood smears were labeled, air-dried, fixed with methanol, stained with Giemsa stain and examined microscopically for presence of Anaplasma spp.

\section{Microscopic examination}

All the smears were examined at $100 \mathrm{X}$ magnification with compound microscope by searching at least 50 fields per slide. The parasites were identified according to the procedure as described by [17].

\section{Statistical analysis}

The collected data were analyzed by conventional percentage and average analysis and chi square analysis to achieve the objectives of the study.

\section{Results}

In the present study, the overall prevalence of anaplasmosis was $19.66 \%(59 / 300 \times 100)$ in clinically symptomatic local and cross breed friesian cattle under field conditions screened by microscopic examination in district Lakki Marwat, KPK Pakistan as presented in (Table 1).

In (Table 2), the age wise prevalence of anaplasmosis is presented where the chisquare analysis has exposed a highly significant $(\mathrm{p}<0.001)$ association between the age of the animal and prevalence of anaplasmosis in cattle. The prevalence rate was higher in young cattle at the age of $(\leq 5$ years) than cattle above five years of age. In 
young animals either having age of 5 years or less than 5 years, the highest prevalence (24.85\%) was recorded than adult ( $\geq 5$ years) where lower prevalence (13.13\%) was recorded. The young animals might have weak immune system while those above five years age have strong immune system and might be immune subsequent clinical infection.

Currently, the highest prevalence of anaplasmosis was recorded in female animals $(22.07 \%)$ than male $(11.59 \%)$ and statistically highly significant $(\mathrm{p}<0.002)$ association was recorded between sex of the animals and prevalence of bovine anaplasmosis after chi-square analysis as presented in (Table 3).

In (Table 4), the breed wise prevalence of anaplasmosis is presented where the chisquare analysis has been exposed a highly significant $(\mathrm{p}<0.0000)$ association between the indigenous pure breed and Cross Holstein Friesian cattle. The prevalence rate was higher in Cross Holstein Friesian cattle $(28.10 \%)$ than Indigenous pure breed cattle $(6.08 \%)$. This may be due to natural resistance in local breeds to ticks and suitable adaptation to harsh environment.

In the present study, the highest prevalence was recorded in the month of June (38\%) followed by May (34\%), March (10\%), January (8\%) while the lowest in the month of February (6\%) and statistically significant $(\mathrm{p}<0.003))$ association was recorded in different months of the year and prevalence of anaplasmosis as presented in (Table 5).

The highest prevalence was recorded in the summer season (36\%) followed by spring $(16 \%)$ while the lowest in the winter season (7\%). Statistical analysis showed highly significant $(\mathrm{p}<0.0000)$ association between prevalence of anaplasmosis and seasons (Table 6).

In the present study, the application of insecticides was also studied where the prevalence was lower $(10.86 \%)$ in those areas where pesticides/ acaricides were regularly used whereas highest prevalence $(23.55 \%)$ was recorded in those area where acaricides were not used. Statistically highly significant $(\mathrm{p}<0.002)$ association was recorded between application/non-application of pesticides and prevalence of anaplasmosis (Table 7).

Table 1. Overall prevalence of anaplasmosis in cattle

\begin{tabular}{|c|c|c|c|}
\hline $\begin{array}{c}\text { Factors } \\
\text { (overall } \\
\text { prevalence) }\end{array}$ & $\begin{array}{c}\text { Total number of cases } \\
\text { examined }\end{array}$ & $\begin{array}{c}\text { Total number of infected } \\
\text { cases }\end{array}$ & $\begin{array}{c}\text { Overall Prevalence } \\
(\%)\end{array}$ \\
\hline $\begin{array}{c}\text { Anaplasmosis in } \\
\text { cattle }\end{array}$ & 300 & 59 & 19.66 \\
\hline
\end{tabular}

Table 2. Age wise prevalence of anaplasmosis in cattle

\begin{tabular}{|c|c|c|c|c|}
\hline Factor(Age) & $\begin{array}{c}\text { Total examined } \\
\text { cases }\end{array}$ & Positive cases & $\begin{array}{c}\text { Prevalence } \\
(\mathbf{\%})\end{array}$ & \multirow{2}{*}{ P. value } \\
\cline { 1 - 3 } Young $(\leq 5$ years $)$ & 165 & 41 & 24.85 & \multirow{2}{*}{$\mathbf{p}<\mathbf{0 . 0 0 1}$} \\
\hline Adult $(\geq 5$ years $)$ & 135 & 18 & 13.13 & \\
\hline
\end{tabular}

$*$ Significant difference $\mathrm{p}<0.05$

Table 3.Sex wise prevalence of anaplasmosis in cattle

\begin{tabular}{|c|c|c|c|c|}
\hline Factor(sex) & Total examined cases & Positive cases & Prevalence $(\boldsymbol{\%})$ & P. value \\
\hline Male & 69 & 8 & 11.59 & \multirow{2}{*}{$\mathbf{p}<\mathbf{0 . 0 0 2}$} \\
\hline Female & 231 & 51 & 22.07 & \\
\hline
\end{tabular}

*Significant difference $\mathrm{p}<0.05$ 
Table 4. Breed wise prevalence of anaplasmosis in cattle

\begin{tabular}{|c|c|c|c|c|}
\hline Factor(Breed) & Total examined cases & Positive cases & Prevalence (\%) & P. value \\
\hline Indigenous pure breed & 115 & 7 & 6.08 & \multirow{2}{*}{ p $<0.0000$} \\
\cline { 1 - 4 } $\begin{array}{c}\text { Crossbred Holstein } \\
\text { Friesian }\end{array}$ & 185 & 52 & 28.10 & \\
\hline
\end{tabular}

*Significant difference $\mathrm{p}<0.05$

Table 5. Month wise prevalence of anaplasmosis in cattle

\begin{tabular}{|c|c|c|c|c|}
\hline Factor( Months) & Total examined cases & Positive cases & Prevalence (\%) & P. value \\
\hline January & 50 & 4 & 8 & \\
\hline February & 50 & 3 & 6 & \multirow{2}{*}{$\mathbf{p}<\mathbf{0 . 0 0 3}$} \\
\hline March & 50 & 5 & 10 & \\
\hline April & 50 & 11 & 22 & \\
\hline May & 50 & 17 & 34 & \\
\hline June & 50 & 19 & & \\
\hline
\end{tabular}

*Significant difference $\mathrm{p}<0.05$

Table 6. Season wise prevalence of anaplasmosis in cattle

\begin{tabular}{|c|c|c|c|c|}
\hline Factor( Months) & Total examined cases & Positive cases & Prevalence (\%) & P. value \\
\hline Winter ( Jan\& Feb) & 100 & 7 & 7 & \multirow{2}{*}{ p<0.0000 } \\
\cline { 1 - 3 } $\begin{array}{c}\text { Spring (March\& } \\
\text { April) }\end{array}$ & 100 & 16 & 16 & \\
\hline $\begin{array}{c}\text { Summer (May\& } \\
\text { June) }\end{array}$ & 100 & 36 & 36 \\
\hline
\end{tabular}

*Significant difference $\mathrm{p}<0.05$

Table 7. Association between application of insecticides/ non-application of insecticides and Prevalence of anaplasmosis

\begin{tabular}{|c|c|c|c|c|}
\hline Factor( Insecticides) & Total examined cases & Positive cases & Prevalence (\%) & \multirow{2}{*}{ P. value } \\
\hline Insecticides used & $\mathbf{9 2}$ & $\mathbf{1 0}$ & $\mathbf{1 0 . 8 6}$ & \multirow{2}{*}{ P $<0.002$} \\
\hline Insecticides not used & $\mathbf{2 0 8}$ & $\mathbf{4 9}$ & $\mathbf{2 3 . 5 5}$ & \\
\hline
\end{tabular}

*Significant difference $\mathrm{p}<0.05$

\section{Discussion}

In the present study, the overall prevalence of anaplasmosis was $19.66 \%$ in cattle showing clinical signs under field conditions and similar results $(18.50 \%)$ were also reported by [18]. Our results are higher than [19] who reported $5.95 \%$ prevalence of subclinical anaplasmosis. On the other hand $[20,21]$ reported higher prevalence $(33 \%)$ and $(70 \%)$ of bovine anaplasmosis respectively than our results. These variations may be due to geographical location, different breeds, hygienic conditions, availability of veterinary services and seasons of sample collection. In the present study, the highest prevalence was observed in young cattle at the age of $(\leq 5$ years) followed by adult cattle $(\geq 5$ years).Similar observations were also reported by $[22,21]$ who reported higher prevalence in adults than young calves. In young animals having age of 5 years or less than 5 years, the highest prevalence $(24.85 \%)$ was recorded than adult $(13.13 \%)$ and statistically highly significant $(\mathrm{p}<0.001)$ association between the age of the animal and prevalence of anaplasmosis was recorded. Our results are close with the findings of [18] who reported (22.72\%) and (20\%) prevalence in young calves at the age of 48 months and 1-24 months respectively. 
However [21] reported higher bovine prevalence $(53.33 \%)$ at the age of three years or above. However [23] reported little higher prevalence $(36.59 \%$ ) in cattle at the age of more than 5 years while $22.95 \%$ at the age less than 3 years of cattle. The young animals might have weak immune system while those above five years age have strong immune system and might be immune consequent clinical infection.

Presently the highest prevalence of anaplasmosis was recorded in female cattle $(22.07 \%)$ than male $(11.59 \%)$ and statistically highly significant $(\mathrm{p}<0.002)$ association was recorded between sex of the animals and prevalence of bovine anaplasmosis. Our findings are also in line with the observations reported by [23] who also reported the highest prevalence in the female cattle $(29.71 \%)$ than the male (12.50\%). Higher prevalence of anaplasmosis in female cattle has been also reported by other researchers [24, 13]. The harshness of anaplasmosis is influenced by sex of the host [25]. The reason for higher prevalence in female animals may be due to lower immunity caused by pregnancy stress, hormonal disturbances, draught power, keeping of female cattle for long period for the purpose of breeding and milking $[26,27]$. The breed wise prevalence was higher in cross Holstein friesian cattle $(28.10 \%)$ than Indigenous pure breed cattle $(6.08 \%)$ and statistically highly significant $(\mathrm{p}<0.0000)$ association was observed between breeds and prevalence of bovine anaplasmosis. Our findings are similar to the statement of [19] who also recorded the highest prevalence of blood protozoan in crossbreed cattle than indigenous breeds. Our results are also close to the findings reported by [23] who also reported the highest prevalence in crossbred Holstein-Friesian cattle (32.38 percent) while lowest in local breeds (10.64 percent). Our study was also supported by $[22,21]$ ) who claimed that different breeds are not equally susceptible to prevalence of anaplasmosis. However some researchers have been suggested that there is no susceptibility to anaplasmosis in different breeds of cattle [28]. This may be due to natural resistance in local breeds to ticks and suitable adaptation to harsh environment. Indigenous cattle are often exposure to constant infections of anaplasmosis and as a result there is development of protection that is responsible for lower occurrence of indigenous cattle [29] Our observations are very similar to [30] who also reported that local breeds are relatively highly resistive than pure friesian breeds. Some researchers stated that crossbred cattle are managed with great attention and less chances of pre exposure to vectors. As a result there is less or no development of immunity against to anaplasmosis [29]. In the present study, the highest prevalence was recorded in the month of June (38\%) followed by May (34\%), March (10\%), January (8\%) while the lowest in the month of February (6\%) and statistically significant $\quad(\mathrm{p}<0.003))$ association was recorded. Our study has been also supported by [31] who observed prevalence of anaplasmosis throughout of the year but the highest incidences were recorded in hot months of the year( May, June, July, August, September, October) because hot and humid environmental conditions are more suitable for the development and reproduction of insects and ticks. Similar observations were also documented in other parts of Pakistan very earlier by [13]. Presently the highest prevalence was recorded in the summer season (36\%) followed by spring (16\%) while the lowest in the winter $(7 \%)$.Statistical analysis showed highly significant $(\mathrm{p}<0.0000)$ association between prevalence of anaplasmosis and seasons. Our results are close with the findings reported by [23] where highest prevalence was recorded in the summer season $(35.23 \%)$ while lowest in winter 
season $(6.06 \%)$. Other researchers also reported similar findings. This protozoal infection is highly prevalent in the summer months of the year. The reason behind high prevalence is that blood sucking flies and ticks are found in abundance in summer season while less in number in winter season which act as a carrier for anaplasma species. In the present study, lower prevalence $(10.86 \%)$ was determined in those areas where pesticides/ acaricides were used regular whereas highest prevalence $(23.55 \%)$ was recorded in those areas where acaricides were not used. Statistically highly significant $(\mathrm{p}<0.0000)$ association was recorded between application/non-application of pesticides and prevalence of bovine anaplasmosis. Similar findings were also reported by [32] who reported the highest prevalence $(33.62 \%)$ in those cattle where acaricides were not used while lower prevalence (17.07\%) was observed in those animals where acaricide were used and significant association was observed.

\section{Conclusion}

In the present study it has been concluded that few factors are responsible for an outbreak of anaplasmosis such as cross breed cattle, young age animals, female animals, summer season, hot months of the year and non uses of acaricides. Ticks and other flies are responsible for parasitic transmission. Bovines need more care toward females and young calves during rearing regarding to anaplasmosis. Therefore it is recommended that proper introduction of resistive breeds, intensive care of young animals at early age of life, more care of female animals, proper preventive measures in summer season and regular use of insecticides can reduce the prevalence of anaplasmosis.

\section{Authors' contributions}

Conceived and designed the experiments: NU Khan, MS Sarwar \& S Ayaz, Performed the experiments: A Ali, Analyzed the data: M Ali \& G Rashid, Contributed reagents/materials/analysis tools: M Hussain, MA Khan\& AU Khan, Wrote the paper: H Ali.

\section{Acknowledgements}

This study has not been received any financial support from government or any non-government organization. We are thankful to the department of livestock and dairy development Lakki Marwat for provision of field staff for collection of samples. We are also thankful to the Director Veterinary Research Institute Peshawar by providing research facilities and other classmates for their support in accomplishment of this study.

\section{References}

1. Rajput ZI, Hu SH, Arijo AG, Habib M \& Khalid MJ (2005). Comparative study of Anaplasma parasites in tick carrying buffaloes and cattle. J Zhejiang UnivSci 6: 1057-1062.

2. Marchette N\& Stiller D (1982). The anaplasmataceae, Bartonellaceae, and Rochalimaea quintana. In: Marchette, NJ, editor. Ecological Relationships and Evolution in the Rickettsiae. CRC Press, Boca Raton, Florida, pp 98-106.

3. Kocan KM, De La Fuente J, Blouin EF \&Garica-Garcia JC (2004). Anaplasma marginale

(Rickettsiales: Anaplasmataceae): Recent advances in defining host-pathogen adaptations of a tick-borne rickettsia. Parasitol 129: 285300.

4. Jongejan F \& Uilenberg G (2004). The global importance of ticks. Parasitol 129: S3-S14.

5. Aubry P \& Geale DW 2011. A review of bovine anaplasmosis. Transbound Emerg Dis 58(1): 1-30.

6. Richey EJ \&Palmer GH. 1990. Bovine anaplasmosis. Compend Contin Educ Pract Vet 12: 1661-1668.

7. Radostitis OM, Gay CC, Blood DC \& Hinchliff KW (2000). In: Veterinary 
Medicine. A Text Book of the Diseases of Cattle, Sheep, Goats and Horses. 9th ed. WB Saunders, London, New York, Philadelephia, pp 1261-126.

8. El-Metenawy TU (2000). Prevalence of blood parasites among cattle at the central area of Saudi Arabia. Vet Parasitol 87: 231-236.

9. Jongejan F \& Uilenberg G (2004). The global importance of ticks. Parasitol 129: S3-S14.

10. De La Fuente, Torina JA, Caracappa S, Tumino G, Furla R, Almazan C \& Kocan KM (2005). Serological and molecular characterization of Anaplasma species infection in farm animals and ticks from Sicily. Vet Parasitol 133: 357-362.

11. Shebish E, Vemulapalli R \& Oseto $C$ (2012). Prevalence and molecular detection of Anaplasma arginale, Babesia bovis and Babesia bigemina cattle from Puntarenas Province, Costa Rica. Vet Parasitol 188: 164-167.

12. Khan MQ, Zahoor A, Jahangir M \& Mirza MA (2004). Prevalence of blood parasites in cattle and buffaloes. Pak Vet J 24: 193-195.

13. Atif FA, Khan MS, Iqbal HJ \& Roheen $T$ (2012). Prevalence of tick-borne diseases in Punjab (Pakistan) and hematological profile of Anaplasma marginale infection in indigenous and crossbred cattle. Pak J of Sci 64: 11-15.

14. Srikant G \& Gaurav N (2014). Problem of ticks and tickborne diseases in India with special emphasis on progress in tick control research: A review. J of Vector Borne Dis 51: 259-27.

15. Ghosh S, Azhahianambi P \& Dela Fuente J (2006). Control of ticks of ruminants, with special emphasis on livestock farming system in India: present and future possibilitiesfor integrated control-a review. Exp Appl Acarol 40: 49-66.
16. Adam KMG, Paul J \& Zaman V (1971). Medical and veterinary Protozoology, Churchill Livingstone Edinburg 200.

17. OIE (2008). Terrestrial Manual, Bovine Anaplasmosis OIE, Paris, France.

18. Kispotta S, Faruk I, Fazlul H, Shajedur R, Adil B, Anowaru $\mathrm{H}$ \&Rezaur $\mathrm{R}(2016)$. Study of prevalence and associated risk factors of anaplasmosis and theileriasis in cattle. Asian $\mathrm{J} \mathrm{Med}$ Biol Res 2(4): 567-576.

19. Samad MA, Bashar SA, Shahidullah M \& Ahmed MU (1989). Prevalence of hemoprotozoan parasites in thecattle of Bangladesh. Indian Vet Med J 13: 50-51.

20. Talukdar MH \& Karim MJ (2001). Subclinical Anaplasma infection in crossbred cattle in Bangladesh. Bangla Vet J 35: 159-160.

21. Chowdhury $S$, Hossain MA, Barua SR \& Islam $S$ (2006). Occurrence of common blood parasites of cattle in Sirajgong Sadar area of Bangladesh. Bangla J Vet Med 4: 143-145.

22. Chakraborti A (2002). A Textbook of Preventive Veterinary Medicine: 3rd Edn, Kalyani

23. Publishers, New Delhi, pp 683.

24. Vetrivel DA, Serma SPJ \& Shilpa JS (2017). A study on predisposing factors for the prevalence of anaplasmosis in dairy cattle. J of Entomol and Zool Stu 5: 1228-1232.

25. Alim MA, Das S, Roy K, Masuduzzaman M, Sikder S \& Hassan MM (2012). Prevalence of hemoprotozoan diseases in cattle population of Chittagong Division, Bangladesh. Pak Vet J 32(2): 221-22.

26. Thrusfield M (1995). Veterinary Epidemiology. Blackwell Science Ltd, a Blackwell Publishing Company 39-41.

27. Kamani J, Sannusi A, Egwu OK, Dogo GI, Tanko TJ \& Kemza S (2010). Prevalence and significance of haemoparasitic infections of cattle in 
North-Central, Nigeria. Vet World 3: 445-448.

28. Kabir MHB, Mondal MMH, Eliyas M, Mannan MA, Hashem MA, Debnath NC, Miazi OF, Mohiuddin C, Kashem MA, Islam MR \& Elahi MF (2011). An epidemiological survey on investigation of tick infestation incattle at Chittagong District, Bangladesh. African $J$ of Microbiolgical Res 5: 346-352.

29. Otim C, Wilson AJ \& Campbell RS (1980). A comparative study of experimental anaplasmosis in Bosindicus and Bostaurus cattle. Australian Vet J 56: 262-266.
30. Siddiki AZ, Uddin MB, Hasan MB, Hossain MF, Rahman MM, Das BC, Sarker MS \& Hossain MA (2010). Coproscopic and haematological approaches to determine the prevalence of helminthiasis and protozoan diseases of Red Chittagong Cattle (RCC) breed in Bangladesh. Pak Vet J 30: 1-6.

31. Taylor MA, Coop Rl \& Wall RL (2007). Veterinary parasitology $3^{\text {rd }}$ edition. Black Well Publishing.

32. Nicholson \&William L (2009). "Ticks (Ixodid) in Gary Mullen \& Lance Durden. Medical and Veterinary Entomology. Academic Press, pp 483532. 